\title{
Modeling and Simulation of Valve-controlled Cylinder System Based on Bond Graph
}

\author{
Wang $Q i^{1}$, Luo Yanjie ${ }^{1} \&$ Wang Jingyue ${ }^{2}$ \\ ${ }^{1}$ School of Mechanical Engineering, University of Shanghai for Science and Technology, China \\ ${ }^{2}$ Bosch Automotive Products (Suzhou) Co. Ltd., China \\ Correspondence: Wang Qi, School of Mechanical Engineering, University of Shanghai for Science and \\ Technology, 516 Jun Gong Road, Shanghai 200093, China. E-mail: wangqi_space@163.com
}

Received: July 13, 2012 Accepted: August 6, $2012 \quad$ Online Published: August 17, 2012

doi:10.5539/mas.v6n9p20 URL: http://dx.doi.org/10.5539/mas.v6n9p20

\begin{abstract}
AMESim is a high performance modeling, simulation and dynamic analysis software. Based on the bond graph theory and the principle of hydraulic control, a simulation model of valve-controlled cylinder system is established by using AMESim software. By changing different factors of the hydraulic system and setting different target wave curves, the system effects with different conditions are discussed and the simulation results provide a theoretical guidance for modeling optimization.
\end{abstract}

Keywords: bond graph, AMESim, simulation, valve-controlled cylinder

\section{Introduction}

For the research on dynamic characteristics of the electro-hydraulic servo system, the most frequently used way is the Transfer Function method, but it is used only when applied for linear system. Themajority of the electro-hydraulic servo systems have nonlinear, time-varying characteristics and lack of the accurate mathematical model, the system must do a linearization processing when using traditional transfer function method, it is inconvenient to study the dynamic characteristics. It has some limitations. At the opposite, after a long period of development and improvement (Norman \& Mark, 2005), the bond graph theory (Paynter, 1959) based on the Principle of Conservation of Energy is becoming more and more useful on the analysis of the electro-hydraulic servo system (Shin \& Sheu, 1991).

\section{The Bond Graph Modeling of Valve-controlled Cylinder}

Based on the rules of hydraulic element and the basic concept of power bond graph, combined with the causal relationship of power bond, integrated with the analysis of power flow of the hydraulic system, and taken into full account the typical nonlinear factor of the system (Wang et al., 2007), a bond graph model for the control system is built, as is shown in Figure 1. And a force closed-loop control (Wang, 2004) bond graph model for Valve-controlled Cylinder is built based on basic equation bond graph model. It is shown in Figure 2.

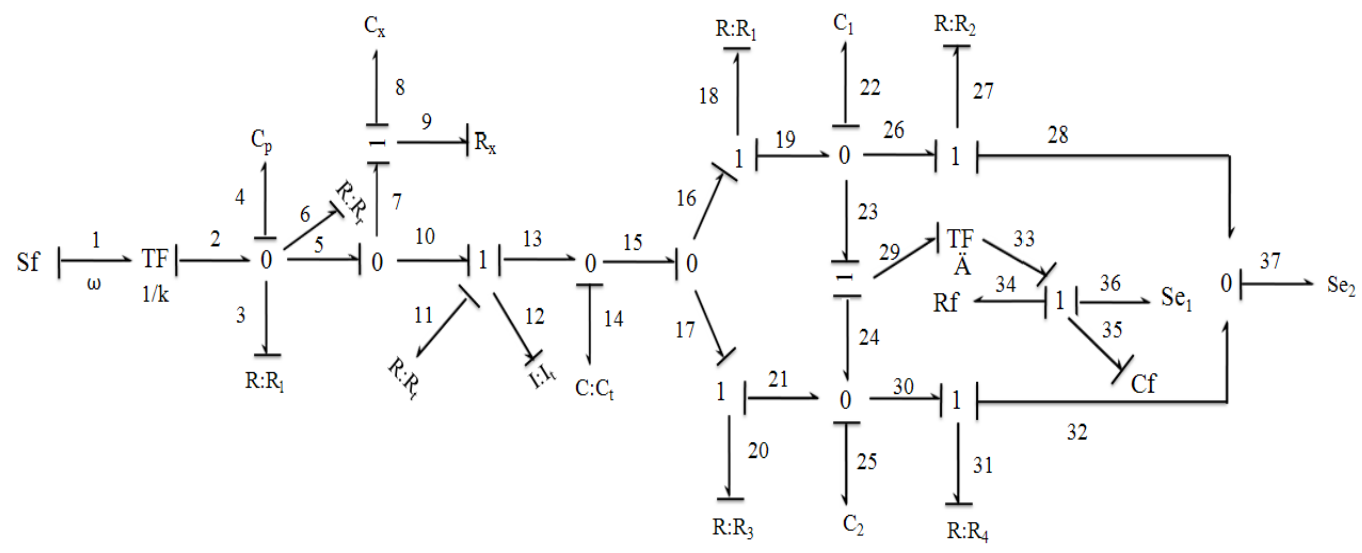

Figure 1. Bond graph model for control system 


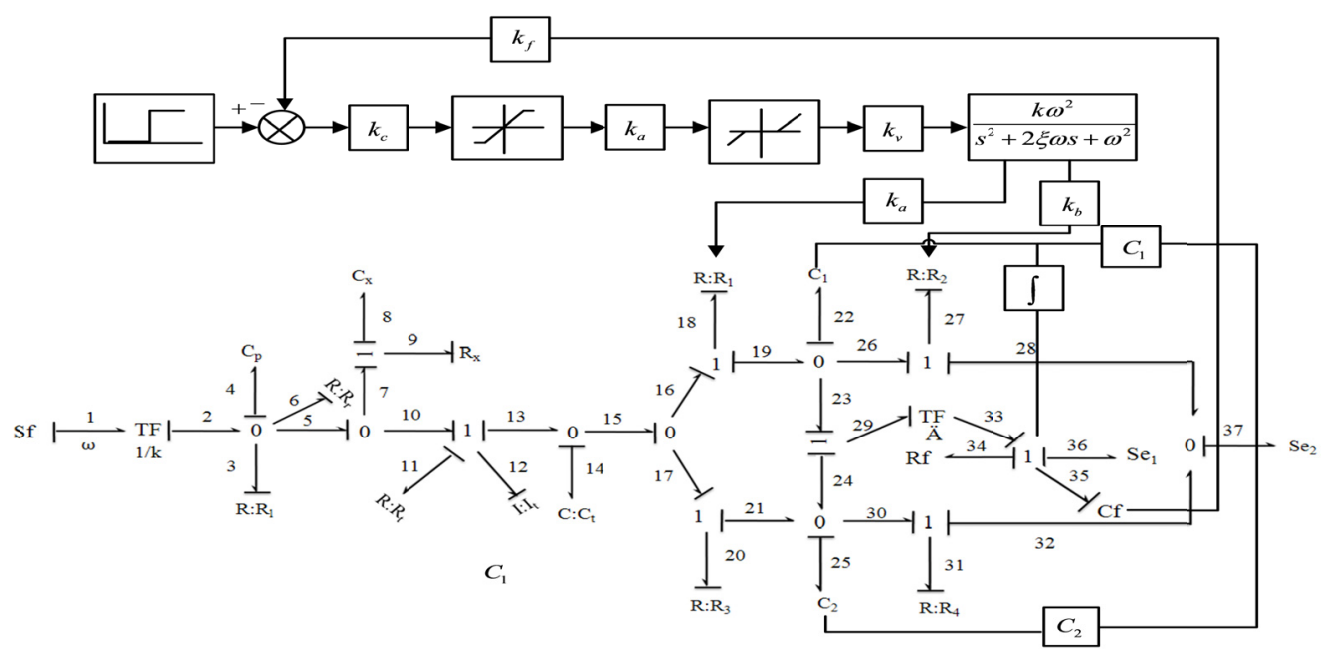

Figure 2. Force closed-loop control bond graph model for Valve-controlled Cylinder

$\mathrm{k}_{\mathrm{c}}$-controller gain, $\mathrm{k}_{\mathrm{a}}$-amplifier gain, $\mathrm{k}_{\mathrm{f}}$-feedback gain, $\mathrm{k}_{\mathrm{v}}-$ flow gain, $\mathrm{C}_{1}, \mathrm{C}_{2}-$ vessel volume, $\mathrm{C}_{\mathrm{f}}-$ elasticity modulus

\section{Draft State Equation of Valve-controlled Cylinder}

Based on the bond graph model of the system, a systematical state equation (Ijiri, 2002) is built by proper selecting the significant state variables. It is first order differential equation, only capacitive elements and inertial elements have derivative and integral relationship in the power bond graph of the hydraulic system (Piche, 2008), so take the two elements as the system state variables. According to the rules of the bond graph, the potential variables of all 0 nodes and the flow variables of all 1 nodes are equal. The system state equations are expressed as:

$$
\left\{\begin{array}{l}
\dot{q}_{4}=f_{2}-f_{3}-f_{6}-f_{5}=\frac{1}{m} s f-\frac{\left(R_{3}+R_{6}+R_{9}\right) q_{4}}{C_{4}}-\frac{1}{c_{8}} q_{8}-\frac{1}{I_{12}} p_{12} \\
\dot{q_{8}}=f_{7}-f_{9}=C_{8} \frac{d e_{8}}{d t}=C_{8} \frac{q_{4}}{R_{9}+R_{3}} \\
\dot{q_{12}}=e_{10}-e_{11}-e_{13}=\frac{1}{C_{4}} q_{4}-\frac{1}{R_{11}} \cdot \frac{1}{I_{11}} P_{12}-\frac{1}{C_{14}} q_{14} \\
\dot{q_{14}}=f_{13}-f_{15}=\frac{1}{I_{12}} p_{12}-R_{18}\left(\frac{1}{C_{14}}-\frac{1}{C_{22}} q_{22}\right)-R_{20}\left(\frac{1}{C_{14}} q_{14}-\frac{1}{C_{25}} q_{25}\right) \\
\dot{q_{22}}=f_{19}-f_{23}-f_{26}=R_{18}\left(\frac{1}{C_{14}} q_{14}-\frac{1}{C_{22}} q_{22}\right)-\frac{A}{I_{35}} p_{35}-R_{27}\left(\frac{1}{C_{22}} q_{22}-s e_{2}\right) \\
\dot{q_{25}}=f_{21}-f_{24}-f_{30}=\frac{R_{20}}{C_{14}} q_{14}-\frac{\left(R_{20}+R_{31}\right)}{C_{25}} q_{25}-\frac{A}{I_{35}} p_{35}+R_{31} s e_{2} \\
\dot{q}_{35}=e_{33}-e_{34}-e_{36}=A\left(\frac{1}{C_{22}} q_{22}-\frac{1}{C_{25}} q_{25}\right)-\frac{1}{R_{34}} \cdot \frac{1}{I_{35}} p_{35}-s e_{1}
\end{array}\right.
$$

$\mathrm{C}_{4}$ - fluid capacity of piston pump, $\mathrm{R}_{3}$-leak fluid resistance, $\mathrm{R}_{6}$ - friction fluid resistance, $\mathrm{C}_{8}$-accumulator fluid resistance, $\mathrm{R}_{9}$-fluid resistance of relief valve, $\mathrm{R}_{11}$-fluid resistance of long pipeline, $\mathrm{I}_{12}$-fluid sensation of long pipeline, $\mathrm{C}_{14}$-fluid capacity of long pipeline, $\mathrm{C}_{22}, \mathrm{C}_{25}$ - fluid capacity of hydraulic cylinder vessel, $\mathrm{R}_{18}, \mathrm{R}_{20}, \mathrm{R}_{27}, \mathrm{R}_{31}$-fluid resistance of servo valve, $\mathrm{A}$-effective action area, $\mathrm{R}_{34}$ - resistive load, $\mathrm{C}_{35}$ - elasticity modulus, e - potential variable, $\mathrm{f}-$ flow variable

\section{The AMESim Modeling of Valve-controlled Cylinder and System Analysis}

\subsection{The Modeling of Valve-controlled Cylinder System}

By using the basic components library in the AMEsim software and combining with the principle of hydraulic 
cylinder system a simulation model is built, as shown in Figure 3.The hydraulic system with electro-hydraulic servo-controlled valve is a typical passive torque servo system (Tanaka et al., 2006), it consists of simulative load system and the carried objects. Thedouble action piston type hydraulic cylinder is executive component of the system and gear rack simulates the steering gear in the model. Rotation angle signals and torque signals of the gear are set as the target signal,the tensionand piston position are measured by sensors as the hydraulic cylinder makes the reciprocating motion. Then they are compared with the setting values. The controller takes the signal asinput and controls flow rate by adjusting the opening size of the servo valveafter the position error is amplified by preamplifier. To optimize system performance with targeted strategy (Yamada \& Shimizu, 2007), the paper will study on several important parameters and the influences onthe system.

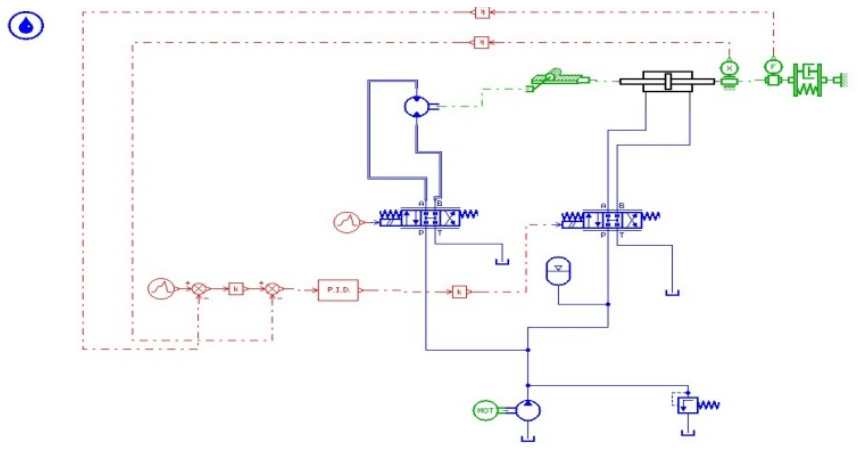

Figure 3. AMESim Model of Valve-controlled Cylinder system

\subsection{Analysis of the Cylinder System and Simulation Results}

The output signal is simulated by AMESim on computer when the input signal is a sine wave which its frequency is $10 \mathrm{~Hz}$, the mutation occurs when the hydraulic cylinder reaching the limit position or inverting and the hydraulic cylinder jittered, as is shown in Figure 4. The force mutation might beinduced by position disturbance of the hydraulic motor and the compressibility of the hydraulic oil, and the gap of the joints may also be the causation. Be familiar with the output force, there are obvious peaks for the pressure and the flow rate of the two hydraulic cylinder vessels, as is shown in Figures 5 and 6. In theory, a sudden change of flow quantity may lead to pressure mutation, it is common and complex.

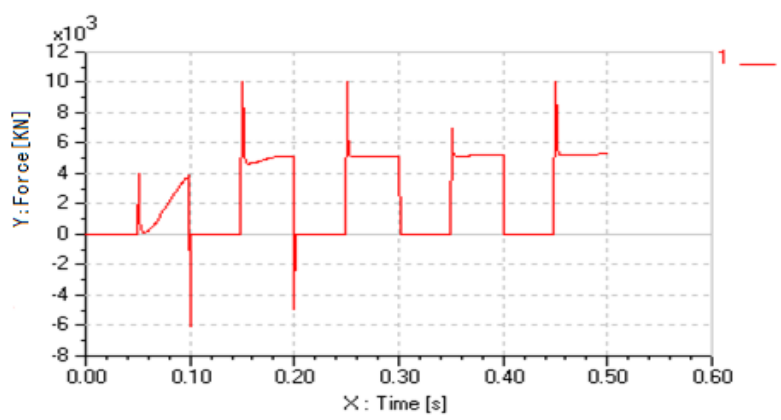

Figure 4. Force curve of piston rod

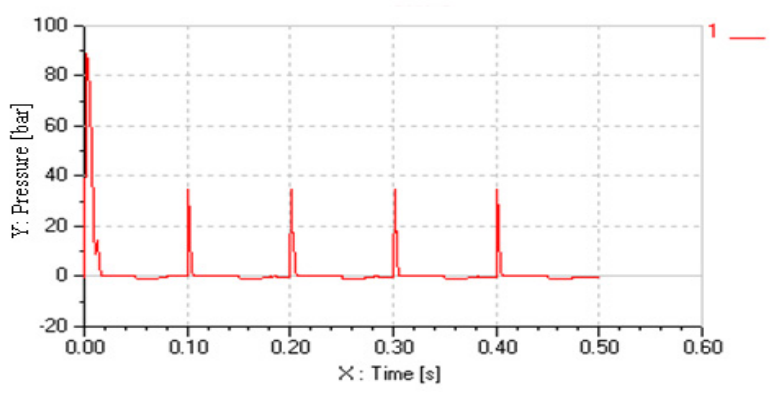

Figure 5. Pressure curve of hydraulic cylinder volume 


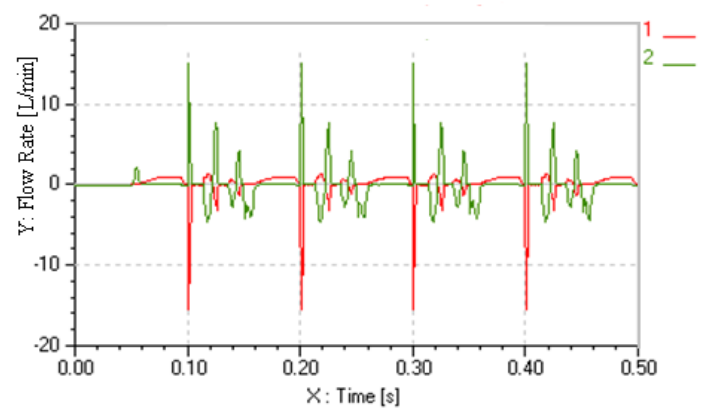

Figure 6. Flow rate curve of hydraulic cylinder

When the input signal is a $2 \mathrm{~Hz}$ sine wave, the simulation results show that as the hydraulic cylinder reaches the limit position, the ripple is apparently displayed in the force signal and it has big overshoot, as shown in Figure 7.

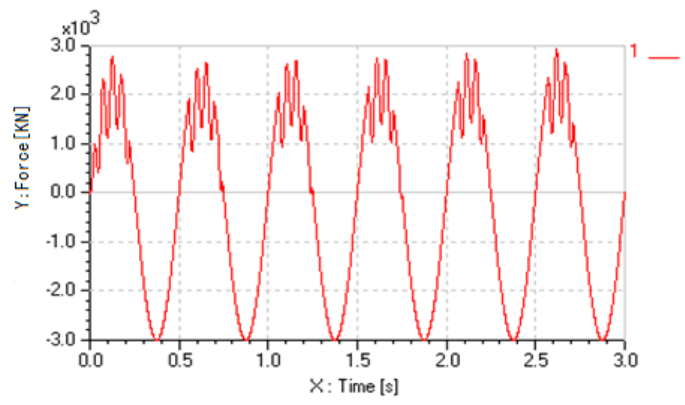

Figure 7. Output signal of force curve

Set the input signal as a $1 \mathrm{~Hz}$ square signal, an extra spike is displayed in the first cycle when the hydraulic cylinder gets to the limit position and the simulation result shows that the model has good tracking performance. As in the third cycle, the amplitude of peak signal becomes smaller than it has before, but there still exist jitter. The results indicate that the amplitude of the tracking curve attenuates seriously and the tracking performance changes to be worse. It shows that the system has good performance with the advantages of stable performance and small system error with little jitter, as is shown in Figure 8. The reasons for this are the limit to interior mechanism and dead zone can lead to response curve mutations when the hydraulic cylinder gets to the limit position. In order to improve the system, the control parameter should be adjusted, at the same time system optimization method is established on the basis of the facts.

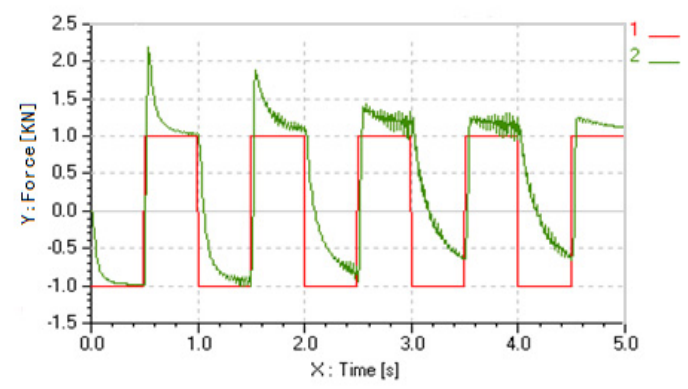

Figure 8. Force tracking curve of hydraulic cylinder

In the hydraulic system, pipes are used to connect the hydraulic source, control mechanism and executor module. The installation location, structure dimension, material, mechanical properties of the pipeline and the physical properties of the brake fluid all have a significant effect on the dynamic performance of the system.

Figure 9 shows the impact of different piping length as the inner diameter is $10 \mathrm{~mm}$ and the wall thickness is 2 
$\mathrm{mm}$. By comparison with simulation curve, it can be found that the longer the length of the pipeline is, the more seriously the hysteresis will be and the system requires more time to be stable. For the length of the pipe is $4 \mathrm{~m}$, it will lead to a long time lag problem (Liu \& $\mathrm{Hu}, 2008$ ).

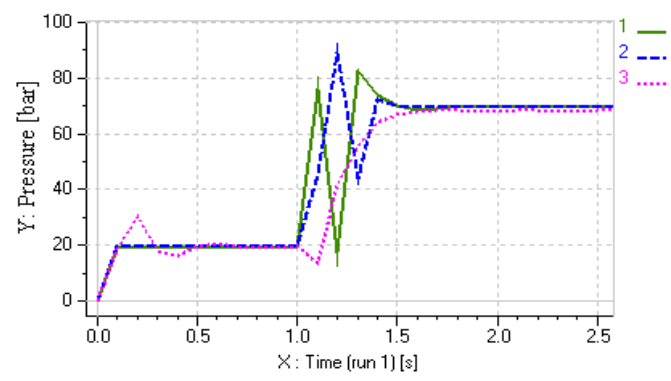

Figure 9. Pressure impact curve of different piping length $(1.1=0.8 \mathrm{~m}, 2.1=2 \mathrm{~m}, 3.1=4 \mathrm{~m})$

Do the same operation as before, Figure 10 shows the impact of different inner diameter of $8 \mathrm{~mm}, 12 \mathrm{~mm}$ and 16 $\mathrm{mm}$ as the pipeline is 4 meters long and wall thickness is $2 \mathrm{~mm}$. In the picture, it can be found that the pressure pulsation changes from high to low and then changes to be high. For the pipe of $8 \mathrm{~mm}$, the pipeline is long and thin and the damping of the pipe is large, so the system has a small peak flow. But for the pipe of $16 \mathrm{~mm}$, the diameter fits the system and it has an effect on reducing the pressure shock. It can be found that there is a lag for different length of the pipe. And Figure 11 shows the pressure impact of different wall thickness of the pipe.

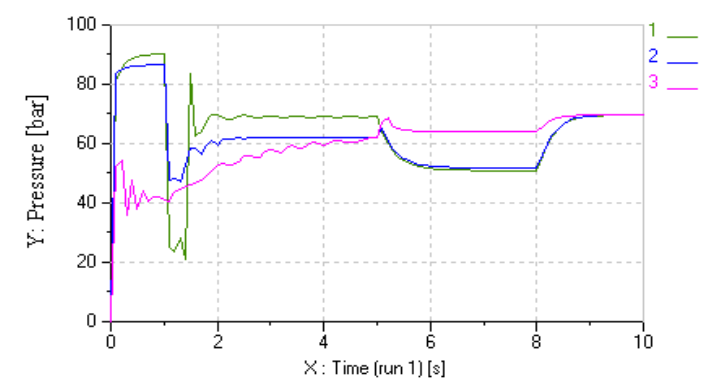

Figure 10. Pressure impact curve of different piping inner diameter(1. $\mathrm{D}=8 \mathrm{~mm}, 2 . \mathrm{D}=12 \mathrm{~mm}, 3 . \mathrm{D}=16 \mathrm{~mm})$

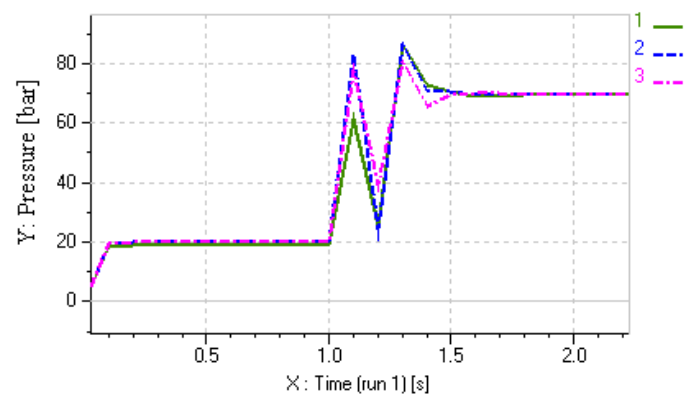

Figure 11.Pressure impact curve of different piping wall thickness $(1 . \delta=1.5 \mathrm{~mm} 2 . \delta=2 \mathrm{~mm} 3 . \delta=3 \mathrm{~mm})$

Besides the geometric parameter of the pipe, the pipe of different material also affects the system. For this situation, suppose that the pipe is a flexible pipe (Guo et al., 2006) as the modulus of elasticity $(\mathrm{E}=10 \mathrm{MPa})$ and the pipe is a rigid pipe $\left(E=2.06 \times 10^{5} \mathrm{MPa}\right)$. Figure 12 is the simulation curve of different material. The figure shows the fluid flows steady as the pipe is a flexible pipe. 


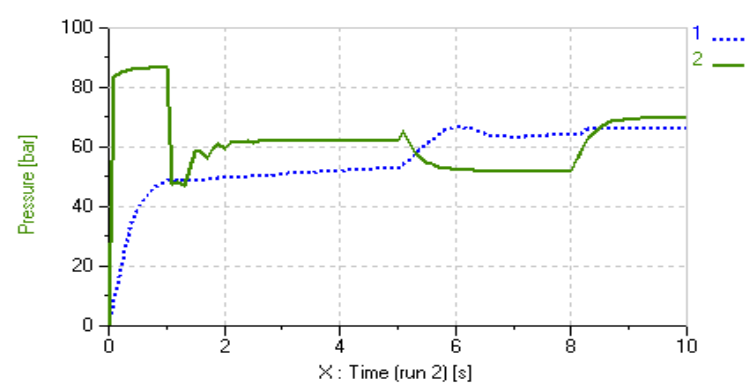

Figure 12. Pressure impact curve of different piping material $\left(1 . \mathrm{E}=10 \mathrm{MPa}, 2 . \mathrm{E}=2.06 \times 10^{5} \mathrm{MPa}\right)$

\section{Conclusion}

This paper studies the Valve-controlled Cylinder system and builds a bond graph model. By simulating on computer, it discusses the hydraulic pressure impact and flow pulsation on the system of different factors, such as length, inner diameter, wall thickness and material of the pipeline. Through the analysis of the simulation results, it can be found:

(1) The length, inner diameter and wall thickness of the pipe all have effect on the peak of the pressure pulsation. The inner diameter has a significant effect on the system in the three factors, the inner diameter should best fit the system, the wall thickness also have a faint effect on the impact.

(2) In the hydraulic cylinder system, the pipeline of the system will cause significant hysteresis phenomena if it is too long and the other two factors have relatively less effect. So in the case of a certain length of the pipe, control strategy should be considered in order to compensate for the effect of the hysteresis problem.

(3) The pressure impact on system is different for different kinds of material. The flexible pipe can partially absorb the pressure shock in the pipeline so the system has a steady pressure. At the opposite, the impact of the rigid pipe will directly affect the actuator and this will cause pressure shock on the system.

(4) Although the pressure impact is unavoidable, pressure peak can be reduced by optimize the characters of the system, and it also can shorten the stabilization time.

All these results provide a theoretical guidance in model optimizationand have a guiding significance on the process design and improvement.

\section{References}

Guo, X. C., Li, M., \& Zhou, Y. W. (2006). Research on stiff problems in dynamic modeling of hydraulic system. Journal of Hydraulics Pneumatics \& Seals, 2, 5-8.

Ijiri, W., \& Tsutsui, T. (2002). Technical Trend of Electric Power Steering Systems. KOYO Engineering Journal, $162,27-31$.

Liu, T. L., \& Hu, G. Q. (2008). Hydraulic System Dynamic Simulation Based on Bond Graph Modeling. Journal of Machine Tool \& Hydraulics, 36, 169-173.

Norman, L. K., \& Mark, S. L. (2005). Vibration analysis of stand F2 of wheeling-pittsburgh's 80-in hot strip mill. Iron and Steel Engineer, 17-25.

Piche, R. P. (2008). Design of Robust Two-Degree-of Freedom Controllers for servos using H8 Theory. Proc., Instn. Mech. Engrs., 205, 299-306.

Shin, M. C., \& Sheu, Y. R. (1991). Adaptive Position Control of an Electro Hydraulic Servo Cylinder. Engineering of Industry, 34, 370-376.

Tanaka, K., Sakamoto, M., Sakou, T., Yamada, Y., Shimizu, A., Arimitsu, Y., \& Uchikado, S. (2006). Improved design scheme of MRAC for electro-pneumatic servo system with additive external force. Proc. of the IEEE Symposium on Emerging Technology and Factory Automation.Kauai, 763-769.

Tanaka, K., Yamada, Y., Shimizu, A., \& Shibata, S. (2007). Multi-rate adaptive pole-placement control for pneumatic servo system with additive external force. Proc of the Int Workshop on Advaced Motion Control.Tsu, 1, 213-218.

Wang, C. X. (2004). Hydraulic control system. Beijing: China Machine Press.

Wang, X., Song, X. G., \& Xue, L. (2007). The Application of Power Bond Graph based on Matlab/Simulink in Hydraulic Dynamic Simulation System. Journal of Coal Mine Machinery, 31,123-127. 